This item was submitted to Loughborough's Research Repository by the author.

Items in Figshare are protected by copyright, with all rights reserved, unless otherwise indicated.

\title{
Cover zone properties influencing acoustic emission due to corrosion
}

PLEASE CITE THE PUBLISHED VERSION

PUBLISHER

(C) Elsevier

LICENCE

CC BY-NC-ND 4.0

\section{REPOSITORY RECORD}

Ing, Matthew J., Simon A. Austin, and Richard Lyons. 2019. "Cover Zone Properties Influencing Acoustic Emission Due to Corrosion". figshare. https://hdl.handle.net/2134/3877. 
This item was submitted to Loughborough's Institutional Repository (https://dspace.lboro.ac.uk/) by the author and is made available under the following Creative Commons Licence conditions.

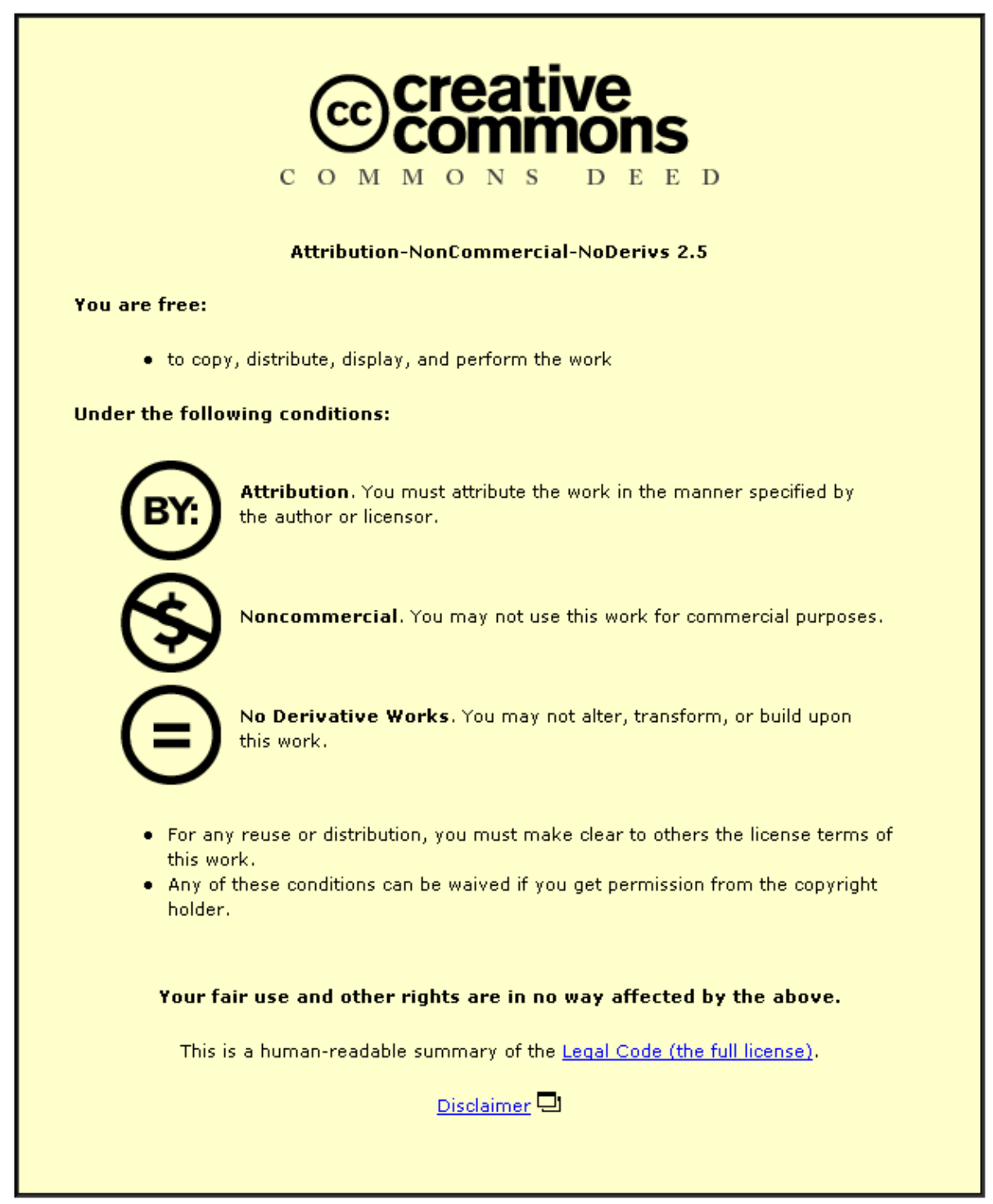

For the full text of this licence, please go to: http://creativecommons.org/licenses/by-nc-nd/2.5/ 


\title{
Cover Zone Properties Influencing
}

\section{Acoustic Emission due to Corrosion}

\begin{abstract}
The deterioration of reinforced concrete is a serviceability problem world-wide. The cover zone plays an important role in the durability and serviceability of concrete and provides the initial barrier to aggressive species. The research presented investigates the potential of acoustic emission (AE) as a means of identifying corrosion at an early stage, before any significant cover damage has occurred. The purpose of part of the study was to identify the influential cover zone factors that affect the magnitude of the acoustic emission measurements per gram of steel loss. Prisms with various combinations of strength, cover thickness, aggregate and rebar diameters were studied to ascertain the important variables likely to be encountered on reinforced structures. The experimental results confirmed that early corrosion, verified by internal visual inspection and mass loss, can be detected by $\mathrm{AE}$ and before any external signs of cracking. They also show that the most influential parameter affecting the $\mathrm{AE}$ measurement is concrete strength, being exponentially related to the AE Energy. Material properties such as cover thickness had a negligible effect on AE Energy during the initial stages of reinforcement corrosion, whereas from this initial work, the rebar diameter indicated a promising relationship with AE Energy per gram of steel loss.
\end{abstract}




\section{Introduction}

The time required to depassivate the surface of the steel in reinforced concrete and thus initiate corrosion, together with the rate at which the corrosion reaction will proceed, are both dependent upon the protection provided by the concrete cover [1] The cover zone of reinforced concrete provides the only barrier to aggressive species which either attack the concrete directly or initiate corrosion of the reinforcement [2]. For example, the concrete cover controls the penetration of $\mathrm{Cl}^{-}, \mathrm{CO}_{2}$ and $\mathrm{O}_{2}$ molecules to the vicinity of the steel, hence increasing the quality of concrete and depth of cover increases the penetration time of $\mathrm{Cl}^{-}$ions to the level of steel and decreases the rate of oxygen diffusion [1]. However, in addition to cover thickness, the rate of diffusion of oxygen and $\mathrm{CO}_{2}$ is also controlled by the degree of pore saturation in the concrete cover [3-5]. It has been shown that the strength of the concrete does not necessarily reflect the durability of the concrete [6].

Corrosion of steel is an electrochemical process, with a number of anode and cathode reactions. The combination of these reactions form the basis of corrosion products, namely $\mathrm{Fe}(\mathrm{OH})_{2}$. Further reactions with oxygen and water present in the cover might form $\mathrm{Fe}(\mathrm{OH})_{3}$ [7], which is of greater volume than the steel. This increase in volume exerts stresses within the concrete, resulting in localised microcracking once the tensile capacity has been exceeded. In some instances, it has been reported that only 10-50 $\mu \mathrm{m}$ of steel corrosion has been sufficient to crack $20 \mathrm{~mm}$ of cover [8]. Depending on the rebar spacing, rebar and cover dimensions, delamination of the concrete cover can occur resulting in a loss of bond with the reinforcement. 
The loss of bonding through delamination of the cover is a serious serviceability issue, hence reliable and early warning of potential cover damage would be of significant benefit. Acoustic Emission (AE) is an inspection technique that detects elastic waves due to material micro-fracture. It has been found that $\mathrm{AE}$ is very sensitive to growth and initiation of cracks in concrete structures [9]. The use of AE as a method to detect corrosion of steel is well documented [10-14]. AE is not an electrochemical method, but by utilising the sensitivity of the technique to the growth and initiation of microcracks $\mathrm{AE}$ is able to identify corrosion by detecting microcracking induced to concrete as a consequence of the corrosion reaction [10]. The ability of concrete to resist the detrimental influence of corrosion is largely dependent upon the material properties of the concrete. However, no evidence of research has been found that investigates the effect of material properties on the magnitude of acoustic emissions. If the technique is to be developed from a laboratory-based tool into a field application, some understanding of the influential and structure specific parameters must be investigated. Therefore any relationship between metal loss and acoustic emission should be investigated.

The focus of this work has been to examine the effects of the cover zone properties on the magnitude of AE Energy against a normalised mass loss.. In addition, the influencing parameters affecting corrosion in concrete have been assessed with a view to enable a more accurate $\mathrm{AE}$ analysis.

\section{Methodology and Experimental Details}




\subsection{Outline}

The testing programme varied the cover thickness, rebar diameter and compressive strength keeping two variables constant. For example, three characteristic strengths were investigated (20, 35 and 50MPa) whilst keeping the rebar diameter and cover constant at $16 \mathrm{~mm}$. Corrosion was induced in the samples using the impressed current method. The subsequent corrosion of the rebar was detected and monitored using acoustic emission, a novel technique that did not perturb the corrosion mechanism or was disturbed by the applied current. After a predetermined period, the prisms were broken open and a visual confirmation of the onset of corrosion was made through measurement of the corroded area. The mass loss was determined gravimetrically and compared to the theoretical values obtained by applying Faraday's Law. The influence of the concrete strength, rebar diameter and cover thickness on the magnitude of the acoustic emissions were investigated against a normalised mass loss.

\subsection{Specimen Manufacture}

Nine series of singly reinforced concrete prisms were cast, with each series comprising eight beams. The material properties of each series are given in Table 1 .

Variations of either rebar diameter, strength, cover or aggregate size between each series revolved around the 'base case’ series, reference 16/35/16. The design of the samples was such that either the influence of the strength, rebar diameter or cover depth could be investigated, with all other factors remaining equal.

The mix proportions and target strengths are given in Table 2. A plain Portland cement (type I) mix was used in each case, with $10 \mathrm{~mm}$ washed river gravel and 
riverbed sand. The average strength of the C20 mixes was $32 \mathrm{MPa}$ with a range of 27$36 \mathrm{MPa}$ and an average standard deviation coefficient of $11 \%$. The average strength of the C35 mix was $54 \mathrm{MPa}$ with a range of 47-60 MPa and an average standard deviation coefficient of $6 \%$ (3.6-10). The C50 mix had a mean strength of $68 \mathrm{MPa}$ (range 60-75) with a standard deviation coefficient of $9 \%$.

The specimen geometry is shown in Fig. 1. The deformed rebars were centrally placed in the horizontal direction of each prism. The cover dimension $c$ is the cover value specific to each series. The cover was controlled on all three sides as shown by using custom made mould insertions that had an accuracy of $\pm 1 \mathrm{~mm}$. The cover on the fourth side was significantly greater to limit any cracking that may occur to the cover thickness being investigated. Prior to casting, scale on the rebar was mechanically removed by means of wire brushing. Using electronic scales, the mass of each bar was then recorded to the nearest 5 milligrams. The weight of the rebars prevented the use of more accurate scales. A length of $20 \mathrm{~mm}$ at each end of the reinforcing bar was wrapped in electrical insulation tape to prevent edge-effects occurring.

The prisms were cast and left in the moulds for 24 hours. All eight beams from each series were cast from the same batch of concrete, and compacted together on a vibrating table together with three cubes to check the compressive strength. Specimens and cubes were stripped and water cured for 28 days, followed by storage in ambient laboratory conditions of $20^{\circ} \mathrm{C} \pm 5^{\circ} \mathrm{C}$, $\mathrm{RH} \sim 50 \%$ for between $56-84$ days. Prior to testing, the prisms were painted with a water-based whitewash to enhance the appearance of any cracks or rust staining should they occur. 


\subsection{Accelerated Corrosion Tests}

A 30V DC power-supply (of type Thurlby Thandar PL320) was set to constant current mode supplying a fixed current of $100 \mu \mathrm{A} / \mathrm{cm}^{2}$ This is reported as corresponding to the maximum corrosion rate for concrete in laboratory conditions [15] and has been used by several researchers in the laboratory $[8,15]$. Spot checks on the output of the power supply were undertaken to ensure that the current output was constant. The rebar was connected to the positive output of the supply, rendering it anodic, whilst the stainless steel plate was connected to the negative terminal, thus cathodic (Fig. 2). Electrical continuity between the anode and cathode was provided by a wet wick saturated in a $5 \% \mathrm{NaCl}$ solution in contact with the base of the prism and the surface of the cathode. The half-cell potential was recorded initially and daily throughout the test duration on a number of the beams.

Four beams in a series were tested simultaneously. A separate power supply and wick system was used for three of the beams to ensure that each beam had a controlled current flow. The fourth beam was used as a control, with no applied current, and was placed on a wet wick of de-ionised water.

\subsection{Acoustic Emission}

Acoustic emission equipment supplied and calibrated by Physical Acoustics Limited was used to monitor the emissions from the concrete prisms described above. The transducers, measuring $25 \mathrm{~mm}$ in diameter and $45 \mathrm{~mm}$ high, were mounted on the top of the specimens using a highly viscous coupling agent as shown in Fig. 2. 
The four prisms were pre-soaked for a seven day period immediately prior to testing by placing on a wet wick soaked with de-ionised water. This was to allow the internal moisture to equilibrate in the cover prior to the start of the test. The samples were then monitored using $\mathrm{AE}$ for a twenty-four hour period prior to the application of the current. The reason for this is three-fold: to ensure that hydration / early - age shrinkage had decayed to a low level that would not influence the results; to ensure that emission due to liquid absorption was not present; and to obtain a typical background level of AE for a specimen. After the initial twenty-four hour period, the current was applied and the samples were continuously monitored for any AE activity.

Termination of the test was determined by monitoring the AE activity over time. The onset of corrosion (defined in the present paper as the transition from the passive state to depassivation and the production of corrosion products) was detected by a sudden increase in AE hits and ABS energy. An AE hit is an emission whose peak amplitude exceeds the set threshold, and ABS Energy is a quantifiable measurement of the energy contained in the hit, measured in atto joules $\mathrm{J}^{-18}$ ). As soon as an increase in the AE occurred, the current was continued for approximately 1 - 3 days to obtain a range of damage and corrosion within the samples. The remaining four prisms from the cast were then used to repeat the test.

One of the initial aims of these tests was to monitor the samples continuously whilst the current was being applied. This served two objectives: (i) most importantly, all the AE activity for a set period of corrosion activity could be collected, enabling an attempt at correlating $\mathrm{AE}$ with mass loss; and (ii) to establish that when there was no 
/ very low levels of emission, no corrosion was occurring. In the case of the latter, it was necessary to occasionally break open samples prior to the onset of significant AE activity for confirmation.

\subsection{Measurement and Quantification of Corrosion}

Upon completion of the tests, each sample was visually examined for cracks, photographed and the cover removed. The surface area of corrosion on the exposed bar was measured and the total length of exposed rebar recorded, before gently removing the corrosion products with a wire brush. The bars were re-weighed to determine any measurable mass loss to a precision of 5 milligrams The total area of exposed steel $\left(A_{e}\right)$ was calculated based on the exposed surface length and the nominal rebar diameter.

The corrosion of steel was assumed to be a direct result of the applied current such that there had been no losses of energy due to heat or sound. This follows Faraday's Law:

$$
\text { Mass Loss }=\frac{\text { Mit }}{z F}
$$

Where $\mathrm{M}=$ Molar mass (55.847 for iron), $i=$ Current (A), $t=$ time (s), $z=$ ionic number (2 for steel) and $F=$ Faraday's Constant $=96,487$.

Corrosion was not uniform over the bar surface but limited to a number of discrete locations with the majority of the surface of the rebar free of corrosion products. As corrosion of steel is not the only chemical reaction possible under the influence of an 
applied current [16], it is considered that two reactions are occurring over different areas of the steel; the corrosion active areas where metal corrodes to form oxide / hydroxide and the corrosion inactive areas where oxygen evolution reduction is probably taking place.

Removal of the corrosion products revealed that the corrosion was in a pre-pitting stage, therefore the area covered by corrosion products can be assumed to be the corrosion active area, denoted $A_{c}$.

Corrosion current $i$ is active over $\left(A_{d} / A_{e}\right)$ area fraction of the surface, where $A_{e}$ is the total exposed surface area and $\left(A_{c} / A_{e}\right)$ is in effect an 'anodic current efficiency' term. Mass loss, therefore, is due to Eq. (2)

$$
\left(A_{c} / A_{e}\right) i
$$

Thus mass loss can be calculated using a modified Faraday equation:

$$
\text { Mass Loss }=\frac{M t}{z F}\left(A_{c} / A_{e}\right) i
$$

For correct application, $t$ denotes the duration of the applied current from the initiation of corrosion, as detected by AE, until termination of the test. Prior to this, it is assumed that the entire surface of the rebar was corrosion inactive.

Applying Eq. (3) to the test results, whilst a degree of scatter exists, a reasonable approximation to gravimetrical mass loss was obtained (Fig. 3), especially at lower mass losses. The scatter is considered acceptable accounting for the errors incumbent in obtaining both measurements and the assumptions made in the theoretical 
calculation. Errors in the gravimetrical measurement may arise due to damage inflicted to the rebar on removal from the concrete and subsequent cleaning, whilst errors in area measurement may introduce errors in the theoretical calculation. The relationship between theoretical and gravimetrical mass loss indicates the reliability of $\mathrm{AE}$ to detect the onset of corrosion. The assumptions and theory are explained in more detail in the following section.

\subsection{Polarisation of samples}

Polarising a rebar, by applying an external current when exposed to the alkaline environment afforded by concrete, will not immediately result in corrosion of the metal surface. The initiation of corrosion on the surface of the bar can only occur if the internal conditions of the concrete alter and the passive layer is broken down. This was achieved by the introduction of chloride ions into the concrete, attracted by the positively charged rebar. The time taken for a critical quantity of chloride ions to reach bar level depends upon the thickness of the cover concrete and its penetrability [17]. This effect of cover is shown in Fig. 4 for each prism at each of the concrete strengths investigated. Many of the individual prism results are superimposed onto each other.

Fig. 4 shows that for a concrete with a 16-mm cover, a period of approximately three days was required for a critical quantity of chloride ions to reach bar level under anodic polarisation of the rebar. Initially, applying a current increases the potential of the steel above the thermodynamic stability range of water. Above this potential, water is oxidised, with the probable evolution of oxygen. Whilst passivity remains 
intact, formation of $\mathrm{Fe}^{++}$ions will not occur, hence Faraday’s Law cannot be applied to determine mass loss.

However, once corrosion has initiated, detected by the onset of AE, it is assumed that both oxygen evolution and corrosion may occur simultaneously during the early stages of corrosion and in this instance the current is used for both corrosion and oxygen evolution. Assuming that the area covered with corrosion products is depassivated, mass loss is due to the 'anodic efficiency' term $\left(A_{c} / A_{e}\right) i$.

\section{Results and Analysis}

\subsection{Evidence of corrosion and resulting $A E$}

The analysis has been based upon using the Absolute Energy (ABS) parameter obtained from the acoustic emission data. The feature of ABS energy is that it records the energy obtained in the whole acoustic emission hit i.e. is threshold independent. The number of hits over time is often used in $\mathrm{AE}$ analysis [10-13,18], however, whilst this is often used to assess the rate of activity of a sample over time, the data is nondimensional and therefore non-quantitative. A useful AE parameter is the amplitude vs. time plot, where the peak amplitude of each hit is plotted against time. This plot enables a quick visual comparison between channels to be taken. Moreover, as amplitude is on a log scale, it gives a clearer indication of the magnitude of the emissions.

Screen shots of amplitude versus time illustrating a control sample with no impressed current, an impressed sample before corrosion has begun and an actively corroding sample under impressed current are presented in Fig. 5(a-c) respectively. Comparing 
Figs. 5(a) and 5(b) with Fig. 5(c), the ability of AE to detect corrosion is clear. The emission in Fig. 5(a and b) is typical of background emission from the concrete, generally of low amplitude and energy. The emission in Fig. 5(c) was typical of emission obtained from a corroding sample over a 24-hour period. However, it is important to note that there was no external evidence of corrosion during this acquisition period as shown for example in Fig. 5, even though corrosion was propagating.

A summary of the key data is presented in Table 3, listing the total hits, ABS energy, corroded area, mass loss (theoretical and gravimetrical) and duration of the corrosion period of the rebar for each sample. Both the hits and ABS Energy values are those recorded during corrosion of the steel. All emissions recorded prior to the initiation of corrosion have been excluded from the analysis. Consequently, the control samples $(\mathrm{D}, \mathrm{H})$ and the samples opened approximately one day before corrosion was expected to begin have not been included in Table 3 as no corrosion products were found. The results hereon in have been divided into three areas to describe the effects of strength, cover depth and rebar diameter.

The extent of corrosion, before termination of the test was low. The electric scales used to measure the mass loss had an accuracy to the nearest 5 milligrams, which in four instances was insufficient to detect any change, hence the theoretical mass losses were substituted for these cases (underlined in Table 3). However, in most cases the gravimetrical weight losses provided independent evidence that corrosion had occurred. Weight loss was accompanied by the development of oxides on the surface 
and the area of this product was used in the theoretical calculation of mass loss using Eq. (3). All further analysis is based upon the gravimetrical mass loss values shown in Table 3. To overcome differences in the level of corrosion that occurred between beams, the data has been normalised by calculating ABS Energy / gram of gravimetrical steel loss.

\subsection{Strength}

The ability of concrete to resist the expansive forces generated by corrosion products is related to the compressive and tensile strength of the material. The tensile strength of concrete is proportionally related to the compressive strength and can be represented by Eq. (4) [19]:

$$
f_{t}=0.36\left(f_{c u}\right)^{0.5}
$$

Where: $f_{t}$ is the direct tensile strength, and $f_{c u}$ is the compressive strength of cubes, both in megapascals.

The relationship between strength and ABS Energy per gram of steel loss for the three strength categories was investigated. Fig. 7 indicates a positive exponential relationship between compressive strength and ABS energy per gram of steel corrosion with a correlation coefficient of 0.79 . Corrosion products deposited at the steel / matrix interface occupy a greater volume than the steel from which they were reduced. This volume increase induces strains at the interface, eventually exceeding the critical local tensile capacity for the matrix. As the local tensile failure occurs, the 
stored strain energy is partly transformed into the surface energy of the new crack face and partly emitted as an acoustic emission. Measuring the release of strain energy in the form of acoustic emission energy have given results that demonstrate an exponential relationship between strain and tensile capacity of the concrete (Fig. 8). This demonstrates the importance of obtaining the characteristic material strengths of any structure being tested. If ABS energy is to be used as a measurement parameter, significant errors may be incorporated into the analysis if the material characteristics are not considered.

Absolute energy levels recorded during the corrosion were not constant with time, but increased in steps, followed by periods of relatively low activity as shown in Fig 9(a). A similar pattern is seen with hits versus time in Fig. 9(b). Comparable behaviour was reported by Dunn et al [12] who considered this a characteristic of periods of crack extension followed by continued corrosion. They believed that once the void provided by a previous crack was filled by new corrosion products, additional cracking then followed. The AE activity recorded in the interim was typically of lower amplitude, hence is of significantly lower energy than the higher amplitude emissions. The lower energy emissions are unlikely to be microcracking due to the frequency of hits and relatively low energy values but may be explained as compression of the pore space or compression of the corrosion product. The magnitude of energy contained in the larger emissions, as shown in Fig. 9(a), may suggest that microcracking within the cover is occurring.

\subsection{Cover Depth}


It is reported by Bascoul [20] that one of the weakest areas in concrete is the interfacial transition zone (ITZ) between cement pastes and aggregates. The different chemical and microstructural characteristics of the ITZ such as composition, an increased porosity and high permeability can influence durability as well as the mechanical properties of the concrete [21,22]. The role of the ITZ in transportation phenomena has been confirmed in terms of an increased diffusivity $[23,24]$ and by an accumulation of ions in the zone $[21,25]$. The higher diffusivity of the ITZ, together with the differences of ionic concentration in the zone, is reported to preferentially attract the iron oxides migrating from the reinforcing bar by a diffusion mechanism following Fick’s Law [21]. Consequently, any damage to the cover resulting from the formation of different oxide phases occurs in this region.

It is a reasonable assumption that a greater cover thickness provides a greater restraining force against microcracking, together with an increase in distance for the potential oxide path through the ITZ. The combination of these factors is likely to increase the ABS energy recorded, per gram of steel loss. However, the data revealed little trend or correlation ( $\mathrm{r}=0.17)$ between cover thickness and ABS Energy (Fig. 10) within the range of cover thickness studied, when keeping rebar diameter and strength constant. However, the natural variance between samples within a single test may disguise any potential relationship. Within the results for the $40 \mathrm{~mm}$ cover series, an anomaly is evident (which has been excluded from the analysis). Corrosion of this sample occurred adjacent to the tape at the end of the rebar where the cover was approximately $20 \mathrm{~mm}$. On this occasion, the oxides were able to permeate around the taped end of the bar to the external end face. This 'leak' of oxides is thought to be responsible for the lower ABS Energy / per gram of steel loss. 
The weak relationship with cover may have been strengthened by increasing the timeperiod of the corrosion reaction, thereby permitting a greater amount of oxide migration into the cover via the ITZ. In the relatively short duration of the reaction, despite the high rate, only very small traces of oxide migration could be detected from visual inspection. Furthermore, with such low levels of mass loss, any error in mass loss measurements can easily distort any trend. The results would suggest that in the initial stages of corrosion, before any significant migration of oxides occur within the ITZ, the cover thickness has little influence on the magnitude of emissions.

It has been noted in previous tests and by other authors $[20,25]$ that corrosion is initiated in locations where aggregates are in close contact with the rebar due to the absence of free lime in these locations. Hence, the accumulation of iron oxides occurs around those aggregates that are in very close proximity to the reinforcing bar. The size of aggregate may influence the preferential failure path of the oxides, hence affect AE. However, from Fig. 11 it is seen that the ratio of maximum aggregate size to thickness of cover was not influential in the magnitude of ABS Energy per gram of steel loss during the initial stages of corrosion.

\subsection{Rebar Diameter}

Damage to the cover resulting from the accumulation of corrosion products is characterised by cracking, delamination or spalling of the concrete, where the mode of failure is a function of the cover / rebar diameter ratio (c/d). This factor is considered the most influential in cracking initiation, where it has been shown that a linear trend exists between the c/d ratio versus attack penetration [27]. In Fig. 12, the c/d ratio was 
varied by keeping the cover thickness and strength constant and varying the rebar diameter. Consequently, by increasing the rebar diameter, the amount of attack penetration required to induce cracking is reduced. This implies that for a given mass loss, prisms with a larger diameter rebar will under go a greater extent of microcracking (leading to macrocracking) which, as shown in Fig. 12, is represented by an increase in ABS Energy per gram of steel loss. The correlation coefficient of $r$ $=0.61$ suggests a reasonable correlation between rebar diameter and ABS Energy, however the scatter present for the $12 \mathrm{~mm}$ diameter rebars introduces an element of uncertainty. Therefore the study was expanded to encompass the various rebar and cover dimensions studied, keeping the compressive strength constant, as illustrated in Fig. 13, which is effectively a combination of Figs. 10 and 12. Through combining the figures an interesting trend is noted where the influence of $\mathrm{c} / \mathrm{d}$ is shown to have a negligible effect when the ratio is greater than approximately 1.1. Such a trend would require further work to substantiate.

\section{Discussion}

The use of AE to detect the early onset of corrosion activity in concrete has been shown to be a reliable laboratory method when used under the conditions presented in this work. Acoustic emission techniques detect transient acoustic waves generated by a sudden change in the local stress field in a material [28] therefore, by definition, the magnitude of energy released is a function of damage and the material. That is to say, if the stress level and material properties are known, the technique also presents the 
capacity to quantitatively assess the damage to a given material, through the detection of stress waves.

For an accurate assessment of damage, in this instance microcracking due to corrosion, material characteristics must be known for a given level of stress. The most important characteristic for the concrete cover zone was identified in Fig. 7, as being the compressive strength. The results show that as a rule of thumb, a $10 \mathrm{MPa}$ increase in compressive strength will result in a 3.5 fold increase of the ABS Energy recorded per gram of steel loss due to corrosion. Consequently, for an equal loss of steel, higher strength concrete will release more energy during micro-fracture than a low strength concrete. Moreover, if the strength of the material is known, then the level of ABS Energy recorded may be used as an indication of the amount of microcracking occurring over the time span of the detection period. In this instance, it is apparent that corrosion detection will be more easily discernible in high strength concretes. The other two variables were found not to influence the AE significantly. There was a poor relationship with cover depth and no relationship with cover / bar diameter ratio. The findings may be because the tests were terminated before significant oxide migration had occurred, as we wanted to break open the specimens to confirm the detection of the early stages of corrosion.

Fig. 14 represents the general relationship between the measured corroded area and gravimetrical mass loss. The relationship suggests a general increase in the area of corrosion with mass loss. This may not always be true as pitting develops. The relationship also supports the findings that corrosion was in a pre-pitting stage. An anomaly is evident indicating that a high mass loss occurred $(0.21 \mathrm{~g})$ corresponding 
with only a small area of corrosion, suggesting that in this instance pitting was occurring. This was not the case, and the spurious measurement may be attributable to damaging the bar on removal. The relationship is stronger at lower levels of corrosion, where the errors associated with measuring the small discrete anodic sites maybe lower. Whilst the duration of the test could be controlled once corrosion had initiated, the extent of corrosion occurring within this time was not under any control, resulting in a large variation in the area of steel corroded.

From Figs. 15 and 16, it can be argued that there is no relationship between ABS Energy and either mass loss or corroded area for the samples tested. AE detects microcracking occurring in the concrete as a consequence of the corrosion reaction, hence is not a directmeasure corrosion rate. The microcracking occurs due to the production of oxides, which have a greater volume than the virgin metal. The volume increase of these oxides is dependent upon the type of oxide produced and on its degree of hydration. Furthermore, migration of these oxides away from the rebar through the ITZ will increase the surface area of the bulk concrete in contact with the oxides, hence may increase the number and frequency of microcracking. Diffusion and hydration of the oxides is independent of corrosion rate, but a function of the porosity of the paste within the cover and time. At high corrosion rates (e.g. $100 \mu \mathrm{A} / \mathrm{cm}^{2}$ ) production of oxide may be greater than diffusion. Hence, at the corrosion rate used for these tests, high values of metal loss occurred without macro cracking of the concrete (verified by the absence of cracking on the surface of the prisms). The influence of higher corrosion currents on the rate of damage occurring to the concrete has also been reported by Alonso et al [27] who sustained corrosion until cracking appeared on the surface of the concrete. They reported that crack widths 
increase up to six times faster at nominal current densities of $10 \mu \mathrm{A} / \mathrm{cm}^{2}$ than at $100 \mu \mathrm{A} / \mathrm{cm}^{2}$. Furthermore, it was found that higher attack penetrations of the steel are necessary at high current densities to achieve a specific crack width than in those specimens tested at lower current densities.

A corrosion current of $100 \mu \mathrm{A} / \mathrm{cm}^{2}$ is towards the limit for naturally occurring corrosion, with values of between 2 and $10 \mu \mathrm{A} / \mathrm{cm}^{2}$ being more commonly measured in real reinforced structures. At these rates, it is hypothesised that the migration of oxides may exceed or equal the rate of production, thereby creating a proportional relationship between $\mathrm{AE}$ and corrosion induced damage to the concrete. Further work is required to investigate the stability of the oxides with time as they accumulate within the cover. If the whole mass of oxide continues to react with the environment under dynamic environmental conditions, an indication of the cumulative volume of steel reduced, together with the damage to the concrete, might be obtainable using AE.

\section{Practical Implications}

The development of the technique as a reliable corrosion detection tool will involve standardising the results to take into account the influential material parameters discussed in this work, the most important of these being the compressive strength of the concrete. The second consideration will be to impress lower corrosion rates to investigate if the rate of ABS energy bears any relationship to the rate of damage induced by differing corrosion rates. 
The results presented have been normalised to give an ABS energy per gram of steel loss value to enable comparisons between beams that have corroded for different durations and over different areas. Due to the localised nature of the corrosion, it was not possible to assess mass loss by duration or area alone. Consequently, an ABS energy per hour value calculated for a beam, averaged over either the entire test duration or a predetermined time, cannot be compared directly with another beam as the total mass losses will be different.

The work presented in this paper has provided an initial assessment of how strength, cover thickness and rebar diameter may influence the ABS energy emitted for a given amount of steel loss. It is acknowledged that only limited data is presented here in which there is evidence of scatter that is inherent in the material and processes, and as such will be naturally reflected in the emissions. The research suggests that ABS Energy is a useful parameter to use to detect corrosion before the onset of visual damage is evident externally. This work has started to answer some of the key questions of how field data may be interpreted when the material factors may vary, giving AE promise as a non-destructive testing technique.

\section{Conclusions}

The use of $\mathrm{AE}$ as a corrosion detection technique within the laboratory has been shown to successfully detect corrosion in a variety of singly reinforced concrete beams exposed to an accelerated corrosion current. The onset of corrosion could be easily identified by a sudden increase in cumulative ABS energy significantly before any visual damage was evident externally. 
This work demonstrates the potential of the $\mathrm{AE}$ technique in detecting reinforcement corrosion. However, the research is extensive in time and effort and though it is believed that within the data presented interesting results have been observed in an area where there is little published data. It is recommended that further work to investigate the effect of lower rates of corrosion with ABS Energy would be a logical progression.

From the work undertaken the following principle conclusions can be drawn:

1. The work has demonstrated the ability of Acoustic Emission as a non-destructive technique to accurately detect reinforcement corrosion at early stages before any external signs (e.g. cracking or staining) of corrosion occur.

2. An exponential, empirical relationship has been established between compressive strength and ABS Energy per gram of steel loss. As a rule of thumb, an increase in compressive strength of $10 \mathrm{MPa}$ will increase the ABS Energy per gram of steel loss 3.5 fold.

3. The exponential relationship between compressive strength and ABS Energy suggests that the $\mathrm{AE}$ technique detects the sudden release of strain energy in concrete, occurring through micro-fracture of the concrete matrix.

4. The thickness of cover was found to have an insignificant effect on the level of ABS Energy per gram of steel loss during the initial stages of corrosion.

5. Increasing the rebar diameter, keeping strength and cover depth constant (35 MPa and $16 \mathrm{~mm}$ respectively) was found to increase the ABS Energy per gram of steel loss. 
6. From the data presented in the paper, the cover / rebar diameter ratio overall had a surprisingly low influence in the magnitude of ABS Energy per gram of steel loss. However, keeping the cover thickness constant and varying the rebar diameter suggested a potential relationship but further investigation is needed.

\section{Acknowledgements}

This work was undertaken at the Centre for Innovative Construction Engineering, Loughborough University. The authors acknowledge the financial assistance from the EPSRC and Balvac Whitley Moran Ltd in addition to technical assistance and specialist equipment loan from Physical Acoustics Limited. Assistance was also given by Atkins Consultants Ltd.

\section{References}

1. A. Bentur, S. Diamond, N.S. Berke, Steel Corrosion in Concrete, Chapman \& Hall, London, 1997.

2. W.J. McCarter, M. Emerson, H. Ezirim, Properties of concrete in the cover zone: developments in monitoring techniques, Mag Conc Res 47 (172) (1995) 243-251.

3. J.N. Envoldsen, C.M. Hansson, Influence of Internal Relative Humidity on the Rate of Corrosion if Steel Embedded in Concrete and Mortar. Cem Concr Res 24 (7) (1994) 1373-1382.

4. W. Lopez, J.A. González, C. Andrade, Influence of Temperature on Service Life of Rebars, Cem Concr Res, 23, (1993) 1130-1140. 
5. J.A. González, W. Lopez, P. Rodriguez, Effects of Moisture Availability on Corrosion Kinetics of Steel embedded in Concrete, Corros 49 (12) (1993) 10041010.

6. H.R. Samaha, K.C. Hover, Influence of Microcracking on the Mass Transport Properties of Concrete, ACI Mater. J. 89 (4) (1992) 416-424.

7. J. Abdul-Hamid, Al-Tayyib, M.S. Khan, Corrosion Rate Measurements of Reinforcing Steel in Concrete by Electrochemical Techniques. ACI Mats J. (1998) 172-177.

8. J.A. González, C. Andrade, C. Alonso, S. Feliu, Comparison of rates of general corrosion and maximum pitting penetration on concrete embedded steel reinforcement, Cem Concr Res 25 (2) (1995) 257-264.

9. M. Ohtsu, T. Okamoto, S. Yuyama, Moment tensor analysis of acoustic emission for cracking mechanisms in concrete, ACI Struct J. 95 (2) (1998) 87-95.

10. M.S. Weng, S.E. Dunn, W.H. Hartt, R.P. Brown, Application of Acoustic Emission to Detection of Reinforcing Steel Corrosion in Concrete, Corros 38 (1) (1982) 9-14.

11. H. Idrissi, A. Limam, Reliability of Acoustic Emission Technique to Assess Corrosion of Reinforced Concrete, J. Acoustic Emission, 18 (2000) 307-313.

12. S.E. Dunn, J.D. Young, W.H. Hartt, R.P. Brown, Acoustic emission characterisation of corrosion induced damage in reinforced concrete, Corros 40 (7) (1984) 339-343.

13. Z. Li, F. Li, A. Zdunek, E. Landis, S.P. Shah, Application of acoustic emission technique to detection of reinforcing steel corrosion in concrete, ACI Mater J. 95 (1) (1998) 68-76. 
14. G. Muravin, Inspection, Diagnosis and monitoring of construction materials and structures by the acoustic emission method, Minerva, London, 2000.

15. C. Andrade, C. Alonso, Cover cracking as a function of bar corrosion: Part 1: Experimental test, Mater Struct, 26 (1993) 453-464.

16. M. Pourbaix, Lectures on Electrochemical corrosion, Plenum Press, New York London, 1973.

17. A.M. Neville, Chloride Attack of Reinforced Concrete: An Overview, Mater Struct 28 (1995) 63-70

18. F. Mansfield P.J. Stocker, Acoustic emission from corroding electrodes, Corros 35 (12) (1979) 541-544.

19. British Standards Institution, Structural Use of Concrete. BSI, London, (1985) BS8110.

20. A. Bascoul, State of the art report - Part 2: Mechanical micro-cracking of concrete, Mater Struct 29 (1996) 67-78.

21. K.K. Aligizaki, M.R. de Rooij, D.D Macdonald, Analysis of iron oxides accumulating at the interface between aggregates and cement paste, Cem Concr Res, 30 (2000) 1941-1945.

22. S. Diamond, J. Huang, The interfacial transition zone: Reality or myth? In: A. Katz, A. Bentur, M. Alexander, G. Arliguie (Eds.), The Interfacial Transition Zone in Cementitious Composites, E\&FN Spon, London, 1998, pp. 3-39.

23. D. Breton, A. Carles-Gibergues, G. Ballivy, J. Grandet, Contribution to the formation mechanism of the transition zone between rock - cement paste, Cem Concr Res 23 (1993) 335-346. 
24. J.P. Ollivier, M. Massat, The effect of the transition zone on transfer properties of concrete, in J.C. Maso (Ed.), Interfacial Transition Zone in Concrete, RILEM Rep 11, E\&FN Spon, London, 1996, pp.117-131.

25. D. Bonen, Features of the interfacial transition zone and its role in secondary mineralization, in A. Katz, A. Bentur, M. Alexander, G. Arliguie (Eds.), The Interfacial Transition Zone in Cementitious Composites, E\&FN Spon, London, 1998, 224-233

26. C.L. Page, K.W.J. Treadaway, Aspects of electrochemistry of steel in concrete, Nature 297 (1982) 109-115.

27. C. Alonso C. Andrade, J. Rodriguez, J.M. Diez, Factors controlling cracking of concrete affected by reinforcement corrosion, Mater Struct 31 (1998) 435-441.

28. A.G. Beattie, Acoustic emission principles and instrumentation, J. Acoustic Emission 2(96) (1983). 


\begin{tabular}{c|c|c|c|c|c}
$\begin{array}{c}\text { Series } \\
\text { Reference }\end{array}$ & $\begin{array}{c}\text { Rebar } \\
\text { Diameter } \\
(\mathrm{mm})\end{array}$ & $\begin{array}{c}\text { Strength } \\
\text { MPA }\end{array}$ & $\begin{array}{c}\text { Cover } \\
(\mathrm{mm})\end{array}$ & $\begin{array}{c}\text { Aggregate } \\
\text { Size } \\
(\mathrm{mm})\end{array}$ & $\begin{array}{c}\text { Dimensions } \\
(\mathrm{mm})\end{array}$ \\
\hline $16 / 35 / 16$ & 16 & 35 & 16 & 10 & $48 \times 70 \times 250$ \\
$16 / 20 / 16$ & 16 & 20 & 16 & 10 & $48 \times 70 \times 250$ \\
$16 / 50 / 16$ & 16 & 50 & 16 & 10 & $48 \times 70 \times 250$ \\
$12 / 35 / 16$ & 12 & 35 & 16 & 10 & $44 \times 70 \times 250$ \\
$20 / 35 / 16$ & 20 & 35 & 16 & 10 & $52 \times 75 \times 250$ \\
$16 / 35 / 25$ & 16 & 35 & 25 & 10 & $66 \times 82 \times 250$ \\
$16 / 35 / 25 *$ & 16 & 35 & 25 & 20 & $66 \times 82 \times 250$ \\
$16 / 35 / 40$ & 16 & 35 & 40 & 10 & $96 \times 100 \times 250$
\end{tabular}

\begin{tabular}{c|c|c|c|c|c|c}
$\begin{array}{c}\text { Characteristic } \\
\text { Strength } \\
(\mathrm{MPa})\end{array}$ & $\begin{array}{c}\text { Cement } \\
\left(\begin{array}{c}\text { content } \\
\left.\mathrm{kg} / \mathrm{m}^{3}\right)\end{array}\right.\end{array}$ & Water & Sand & Aggregate & $\begin{array}{c}\text { Target } \\
\text { Strength } \\
(\mathrm{MPa})\end{array}$ & $\begin{array}{c}\text { Average } \\
\text { Cube } \\
\text { Strength } \\
(\mathrm{MPa})\end{array}$ \\
\hline 20 & $1(316)$ & 0.57 & 2.06 & 3.8 & C28 & 32 \\
35 & $1(400)$ & 0.45 & 1.57 & 2.9 & C43 & 54 \\
35 & $1(390)$ & 0.41 & 1.2 & $3.43(20 \mathrm{~mm})$ & C43 & 57 \\
50 & $1(545)$ & 0.33 & 0.6 & 2.4 & C58 & 68
\end{tabular}

Table 2: Mix Proportions by weight 


\begin{tabular}{|c|c|c|c|c|c|c|c|}
\hline \multicolumn{2}{|c|}{$\begin{array}{l}\text { Specimen } \\
\text { Reference }\end{array}$} & $\begin{array}{l}\text { Hits } \\
5.7 \mathrm{e} 3\end{array}$ & $\begin{array}{c}\begin{array}{c}\text { ABS } \\
\text { Energy } \\
\text { (aJ) }\end{array} \\
1.40 \mathrm{e} 6\end{array}$ & $\begin{array}{c}\begin{array}{c}\text { Gravi- } \\
\text { metrical } \\
\text { Mass Loss } \\
\text { (g) }\end{array} \\
0.11\end{array}$ & $\begin{array}{l}\text { Theoretical } \\
\text { Mass Loss } \\
\text { (g) } \\
0.011\end{array}$ & $\begin{array}{c}\begin{array}{c}\text { Duration } \\
\text { of } \\
\text { corrosion } \\
\text { (s) }\end{array} \\
108000\end{array}$ & $\begin{array}{r}\begin{array}{c}\text { Area } \\
\text { corroded } \\
\left(\mathbf{c m}^{2}\right)\end{array} \\
\\
2.6\end{array}$ \\
\hline $12 / 35 / 16$ & $\begin{array}{l}\text { A } \\
B \\
C \\
\text { E } \\
F \\
\text { G }\end{array}$ & $\begin{array}{l}5.7 \mathrm{e} 3 \\
4.2 \mathrm{e} 2 \\
4.7 \mathrm{e} 2 \\
1.4 \mathrm{e} 4 \\
6.2 \mathrm{e} 2 \\
6.6 \mathrm{e} 2 \\
\end{array}$ & $\begin{array}{l}1.40 \mathrm{e} 6 \\
1.14 \mathrm{e} 7 \\
2.35 \mathrm{e} 7 \\
1.36 \mathrm{e} 8 \\
1.42 \mathrm{e} 8 \\
1.03 \mathrm{e} 7\end{array}$ & $\begin{array}{l}0.11 \\
0.02 \\
0.04 \\
0.01 \\
0.04 \\
0.02 \\
\end{array}$ & $\begin{array}{r}0.011 \\
0.0039 \\
0.014 \\
0.025 \\
0.011 \\
0.015\end{array}$ & $\begin{array}{l}108000 \\
133200 \\
117000 \\
137520 \\
115000 \\
121000 \\
\end{array}$ & $\begin{array}{l}2.6 \\
0.8 \\
3.0 \\
4.9 \\
2.5 \\
3.2\end{array}$ \\
\hline $16 / 50 / 16$ & $\begin{array}{l}\text { A } \\
\text { B } \\
\text { C } \\
\text { E } \\
\text { F }\end{array}$ & $\begin{array}{l}6.5 \mathrm{e} 5 \\
5.6 \mathrm{e} 3 \\
5.5 \mathrm{e} 3 \\
4.4 \mathrm{e} 4 \\
2.8 \mathrm{e} 4\end{array}$ & $\begin{array}{l}5.50 \mathrm{e} 9 \\
8.11 \mathrm{e} 7 \\
1.32 \mathrm{e} 8 \\
5.50 \mathrm{e} 9 \\
8.05 \mathrm{e} 8\end{array}$ & $\begin{array}{l}0.11 \\
0.01 \\
0.17 \\
0.27 \\
0.34\end{array}$ & $\begin{array}{r}0.13 \\
0.024 \\
0.04 \\
0.20 \\
0.13\end{array}$ & $\begin{array}{r}216000 \\
146400 \\
86400 \\
176000 \\
176000\end{array}$ & $\begin{array}{r}21.0 \\
5.5 \\
14.2 \\
40.0 \\
25.4\end{array}$ \\
\hline 20/35/16 & $\begin{array}{l}\text { A } \\
B \\
C \\
E\end{array}$ & $\begin{array}{l}2.9 \mathrm{e} 4 \\
6.5 \mathrm{e} 3 \\
3.4 \mathrm{e} 4 \\
7.2 \mathrm{e} 3\end{array}$ & $\begin{array}{l}4.19 \mathrm{e} 8 \\
1.77 \mathrm{e} 9 \\
1.16 \mathrm{e} 8 \\
2.02 \mathrm{e} 8 \\
\end{array}$ & $\begin{array}{l}0.02 \\
0.03 \\
0.01 \\
0.04\end{array}$ & $\begin{array}{r}0.02 \\
0.01 \\
0.01 \\
0.106 \\
\end{array}$ & $\begin{array}{r}125000 \\
172000 \\
86400 \\
205000\end{array}$ & $\begin{array}{r}6.8 \\
1.4 \\
3.4 \\
15.9 \\
\end{array}$ \\
\hline $16 / 20 / 16$ & $\begin{array}{l}\text { A } \\
\text { B } \\
\text { C } \\
\text { E }\end{array}$ & $\begin{array}{l}1.8 \mathrm{e} 3 \\
1.5 \mathrm{e} 2 \\
0.3 \mathrm{e} 2 \\
3.8 \mathrm{e} 2\end{array}$ & $\begin{array}{l}1.54 \mathrm{e} 6 \\
1.60 \mathrm{e} 6 \\
7.60 \mathrm{e} 3 \\
2.87 \mathrm{e} 6\end{array}$ & $\begin{array}{r}0.21 \\
0.02 \\
0.00015 \\
0.0033 \\
\end{array}$ & $\begin{array}{r}0.01 \\
0.012 \\
0.00015 \\
0.0033\end{array}$ & $\begin{array}{r}194000 \\
242000 \\
21000 \\
96000 \\
\end{array}$ & $\begin{array}{l}1.4 \\
1.6 \\
0.2 \\
1.2\end{array}$ \\
\hline $16 / 35 / 25$ & $\begin{array}{l}\text { A } \\
B \\
C \\
E\end{array}$ & $\begin{array}{l}2.6 \mathrm{e} 2 \\
1.5 \mathrm{e} 2 \\
6.0 \mathrm{e} 2 \\
3.7 \mathrm{e} 3\end{array}$ & $\begin{array}{l}2.79 \mathrm{e} 7 \\
3.00 \mathrm{e} 5 \\
3.20 \mathrm{e} 7 \\
5.85 \mathrm{e} 7\end{array}$ & $\begin{array}{r}\frac{0.0019}{0.00022} \\
0.05 \\
0.10\end{array}$ & $\begin{array}{r}0.0019 \\
0.00022 \\
0.056 \\
0.081\end{array}$ & $\begin{array}{r}69000 \\
40000 \\
158400 \\
179900\end{array}$ & $\begin{array}{r}1.1 \\
0.2 \\
12.6 \\
16.0 \\
\end{array}$ \\
\hline $16 / 35 / 25 *$ & $\begin{array}{l}\text { A } \\
B \\
C \\
E\end{array}$ & $\begin{array}{l}5.3 \mathrm{e} 3 \\
3.7 \mathrm{e} 3 \\
1.6 \mathrm{e} 4 \\
7.2 \mathrm{e} 3\end{array}$ & $\begin{array}{l}8.29 \mathrm{e} 7 \\
5.90 \mathrm{e} 6 \\
5.35 \mathrm{e} 7 \\
2.61 \mathrm{e} 8\end{array}$ & $\begin{array}{l}0.10 \\
0.01 \\
0.02 \\
0.07 \\
\end{array}$ & $\begin{array}{r}0.064 \\
0.0051 \\
0.016 \\
0.066\end{array}$ & $\begin{array}{l}225000 \\
231000 \\
169000 \\
228000\end{array}$ & $\begin{array}{r}9.6 \\
1.4 \\
3.6 \\
10.4\end{array}$ \\
\hline $16 / 35 / 16$ & $\begin{array}{l}\text { A } \\
B \\
C \\
\text { E } \\
F\end{array}$ & $\begin{array}{l}3.6 \mathrm{e} 3 \\
1.4 \mathrm{e} 4 \\
5.9 \mathrm{e} 3 \\
7.5 \mathrm{e} 3 \\
6.2 \mathrm{e} 3\end{array}$ & $\begin{array}{l}3.76 \mathrm{e} 7 \\
2.19 \mathrm{e} 8 \\
1.52 \mathrm{e} 8 \\
3.20 \mathrm{e} 7 \\
7.35 \mathrm{e} 7\end{array}$ & $\begin{array}{l}0.01 \\
0.16 \\
0.10 \\
0.11 \\
0.02\end{array}$ & $\begin{array}{r}0.0059 \\
0.078 \\
0.031 \\
0.059 \\
0.023\end{array}$ & $\begin{array}{r}57000 \\
174000 \\
89000 \\
178000 \\
172936\end{array}$ & $\begin{array}{r}3.4 \\
16.1 \\
13.0 \\
11.7 \\
4.7\end{array}$ \\
\hline $16 / 35 / 40$ & $\begin{array}{l}\text { A } \\
\text { B } \\
\text { C }\end{array}$ & $\begin{array}{l}8.6 \mathrm{e} 2 \\
1.4 \mathrm{e} 3 \\
1.6 \mathrm{e} 3 \\
\end{array}$ & $\begin{array}{l}7.05 e 8 \\
2.29 e 8 \\
2.73 e 7\end{array}$ & $\begin{array}{l}0.05 \\
0.06 \\
0.08 \\
\end{array}$ & $\begin{array}{l}0.046 \\
0.053 \\
0.068 \\
\end{array}$ & $\begin{array}{l}228000 \\
479000 \\
421000\end{array}$ & $\begin{array}{l}7.0 \\
4.0 \\
5.5\end{array}$ \\
\hline
\end{tabular}

Table 3: Key Data

* Denotes 20 mm aggregate 
Figure 1 Specimen Dimensions

Figure 2 Accelerated corrosion and AE test set-up

Figure 3 Relationship between theoretical and gravimetrical mass loss.

Figure 4 Effect of Cover on Initiation Time

Figure 5: Amplitude Vs Time

Figure 6: Internal and External View

Figure 7 Influence of compressive strength on ABS energy per gram of steel loss

Figure 8 Influence of tensile strength on ABS energy / gram of steel loss

Figure 9(a): ABS Energy over Time

Figure 9(b): Hits over Time

Figure 10 Influence of cover thickness on ABS energy per gram of steel loss

Figure 11 Influence of cover / aggregate ratio

Figure 12 Influence of rebar diameter on ABS energy per gram of steel loss

Figure 13 Influence of cover / depth ratio on ABS Energy / gram of steel loss

Figure 14 Relationship between corroded area and mass loss

Figure 15 Total ABS Energy vs. Mass Loss

Figure 16 Total ABS Energy vs. Area of Corrosion 


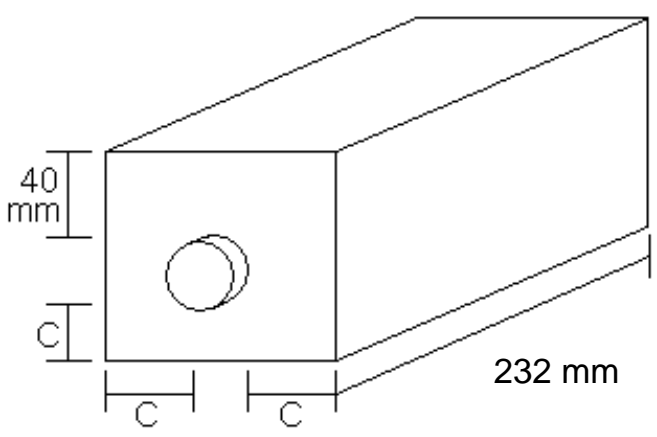

Figure 1 Specimen Dimensions (note rebar is centred horizontally) 


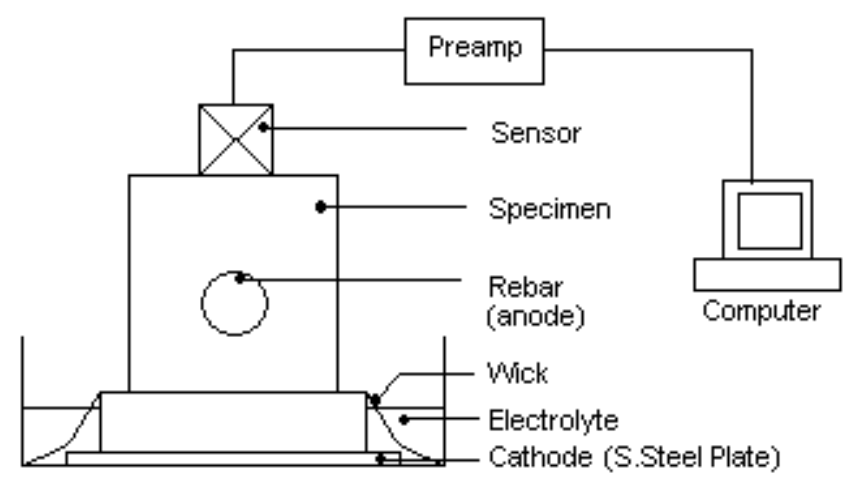

Figure 2 Accelerated corrosion and AE test set-up 


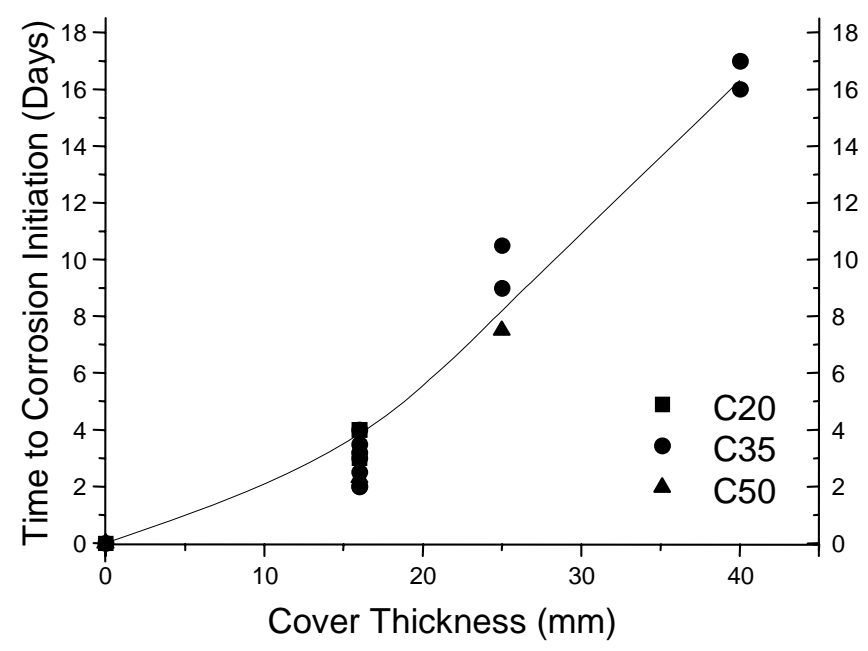

Figure 4 Effect of Cover on Initiation Time 

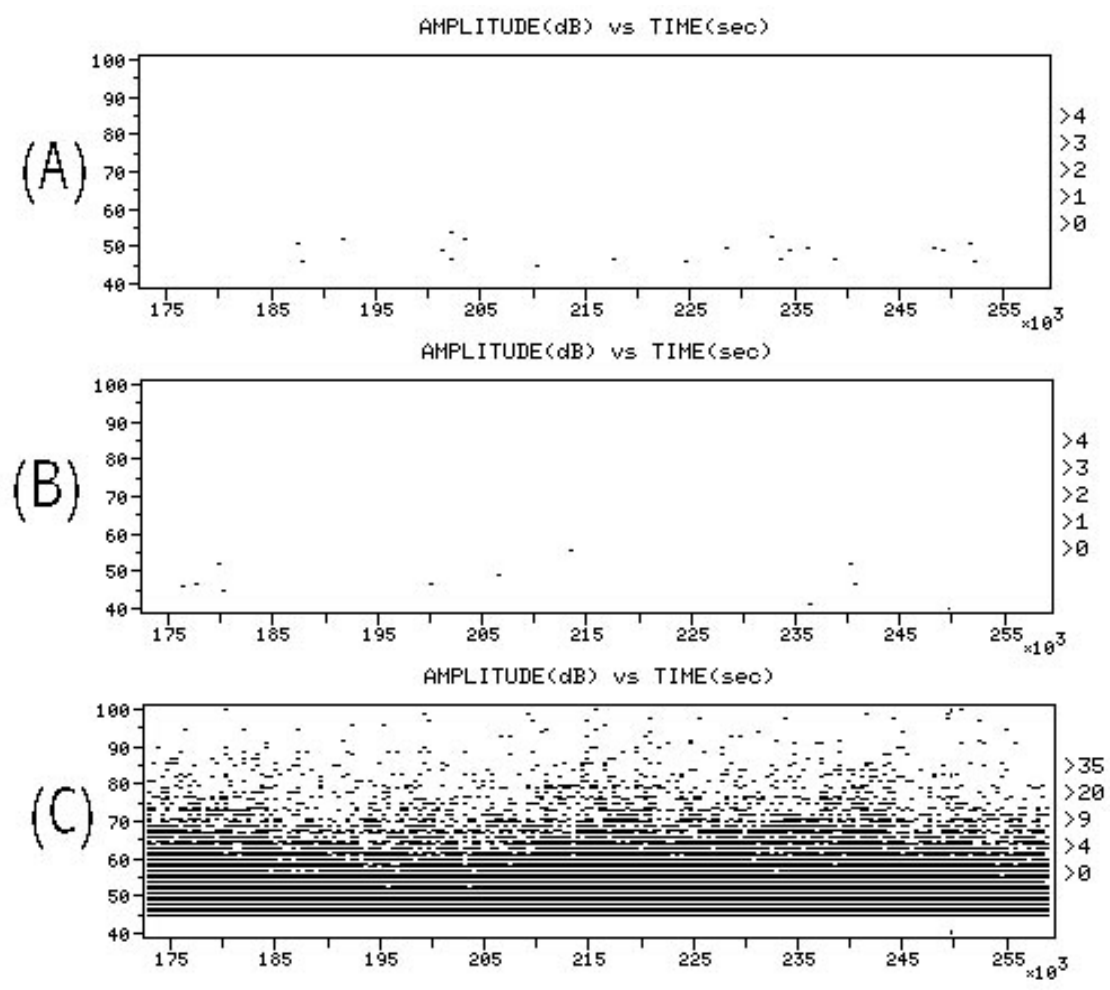

Figure 5: Amplitude Vs Time 

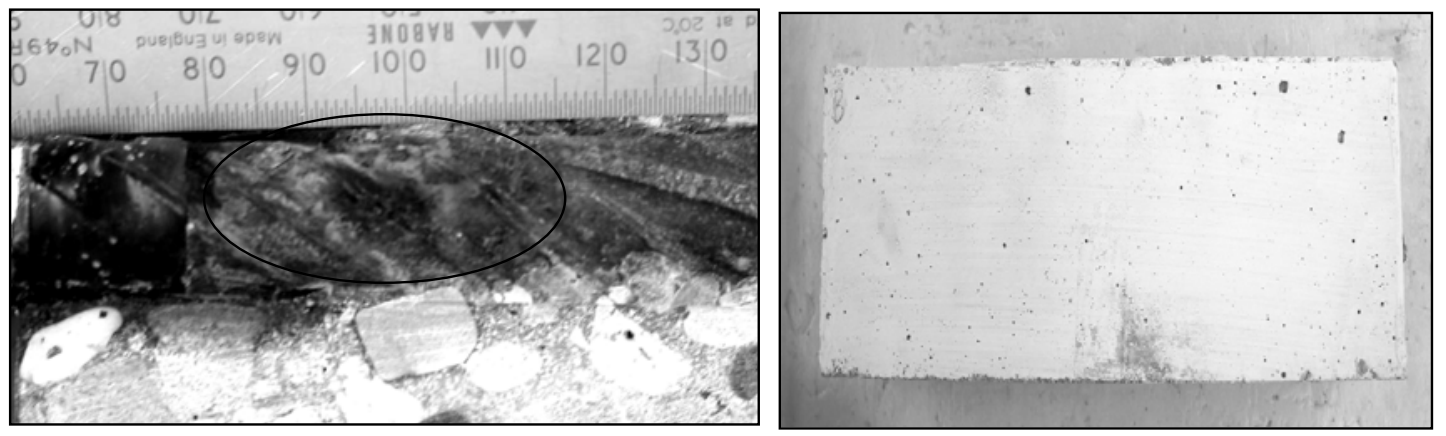

Figure 6: Internal and External View 


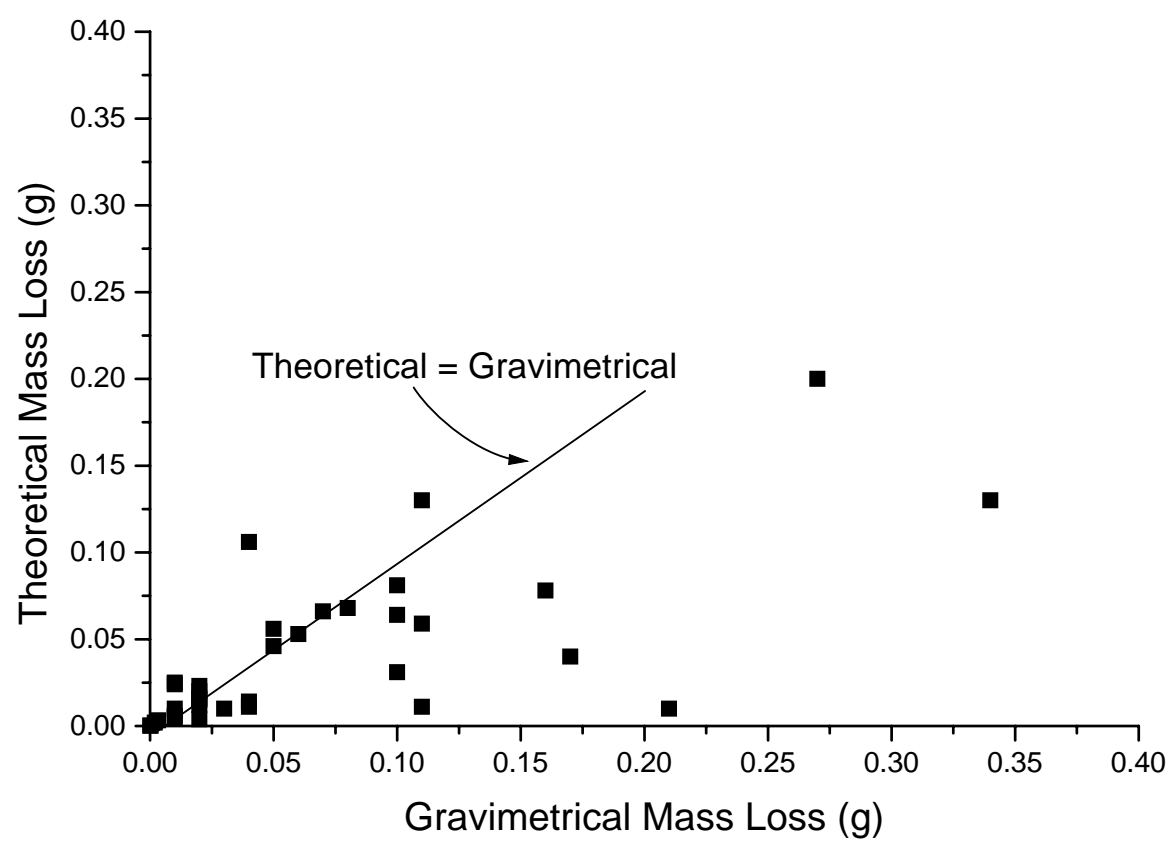

Figure 3 Relationship between theoretical and gravimetrical mass loss. 


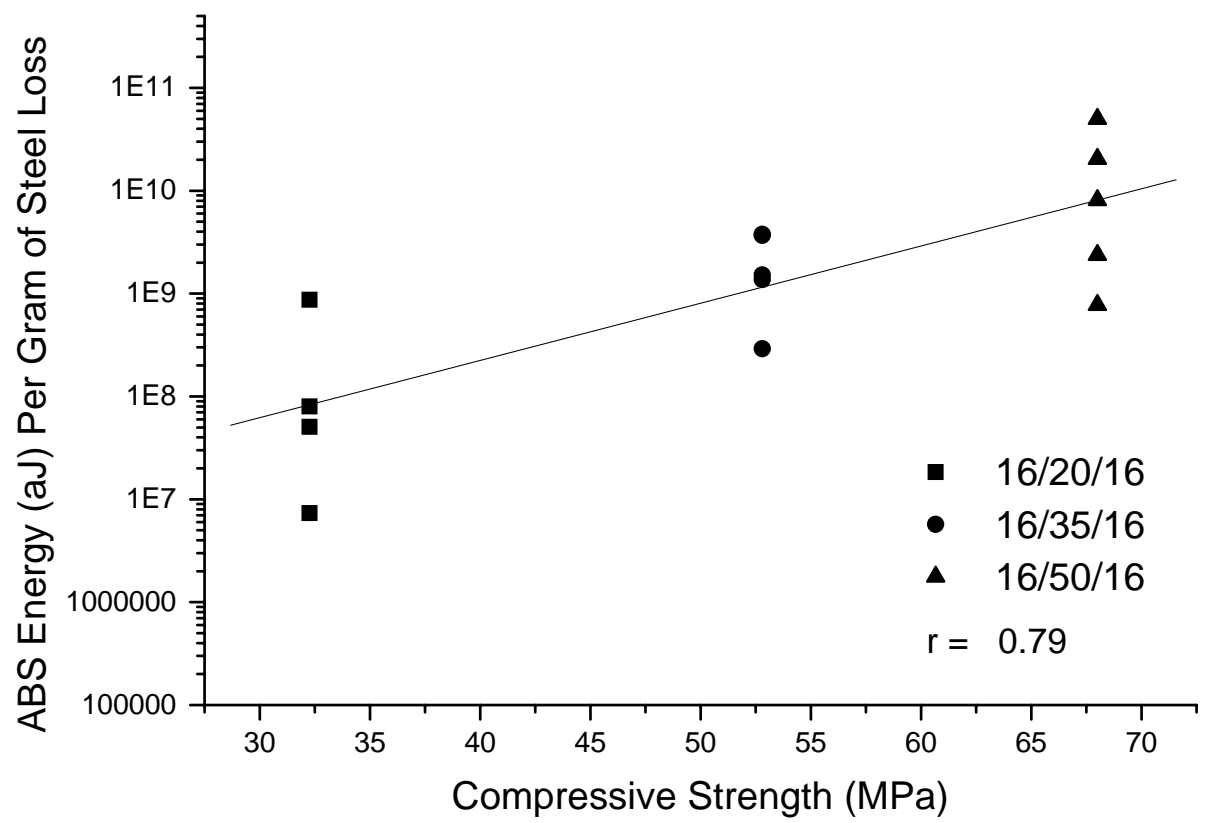

Figure 7 Influence of compressive strength on ABS energy / gram of steel loss 


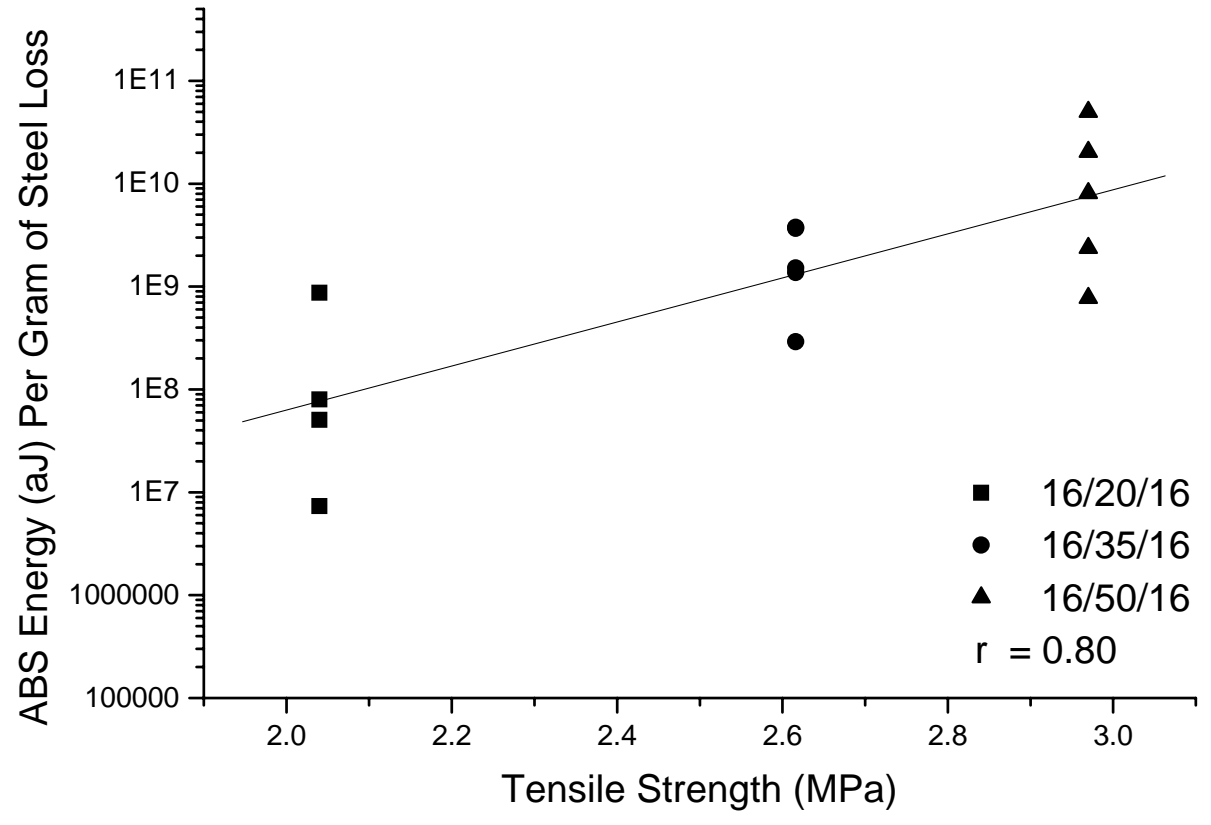

Figure 8 Influence of tensile strength on ABS energy per gram of steel loss 


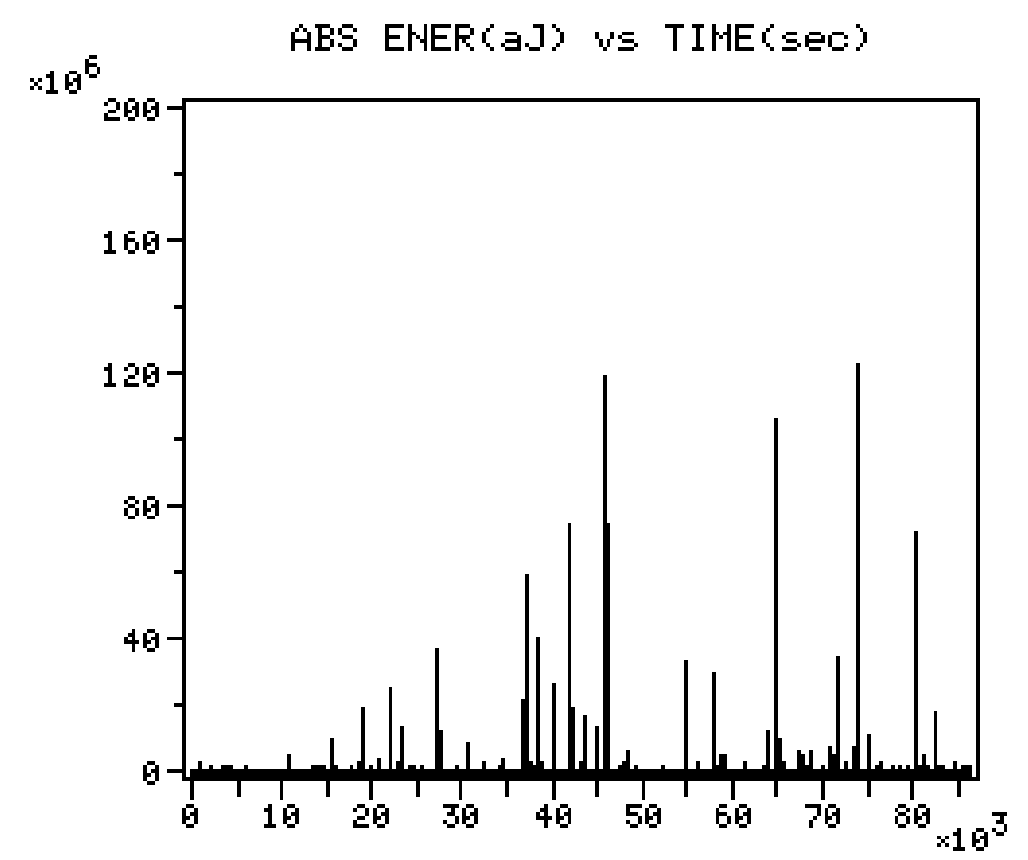

Figure 9(a): ABS Energy over Time 
HITS vS TIHE (SES)

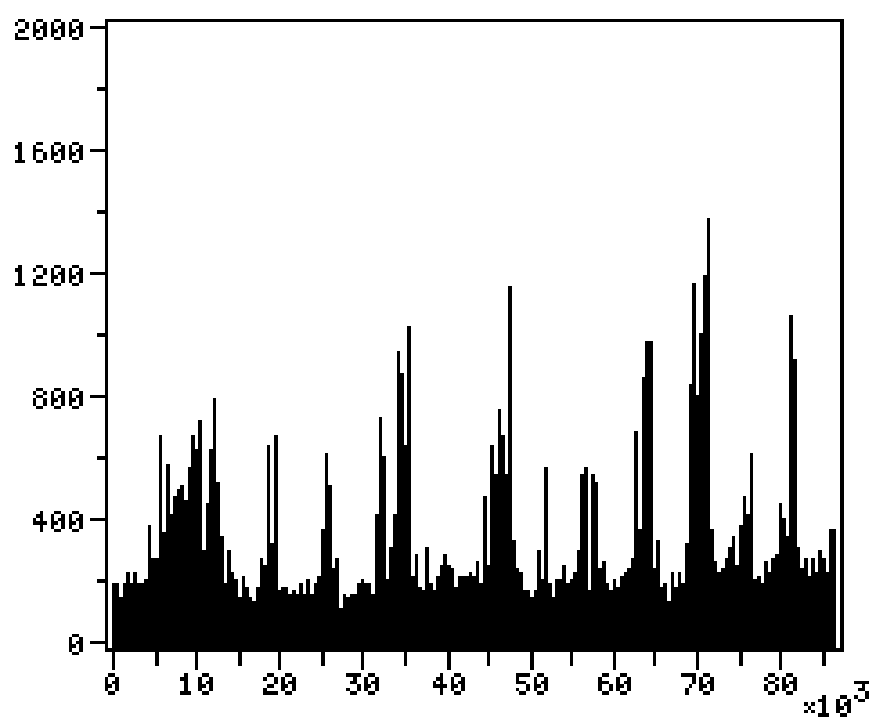

Figure 9(b): Hits over Time 


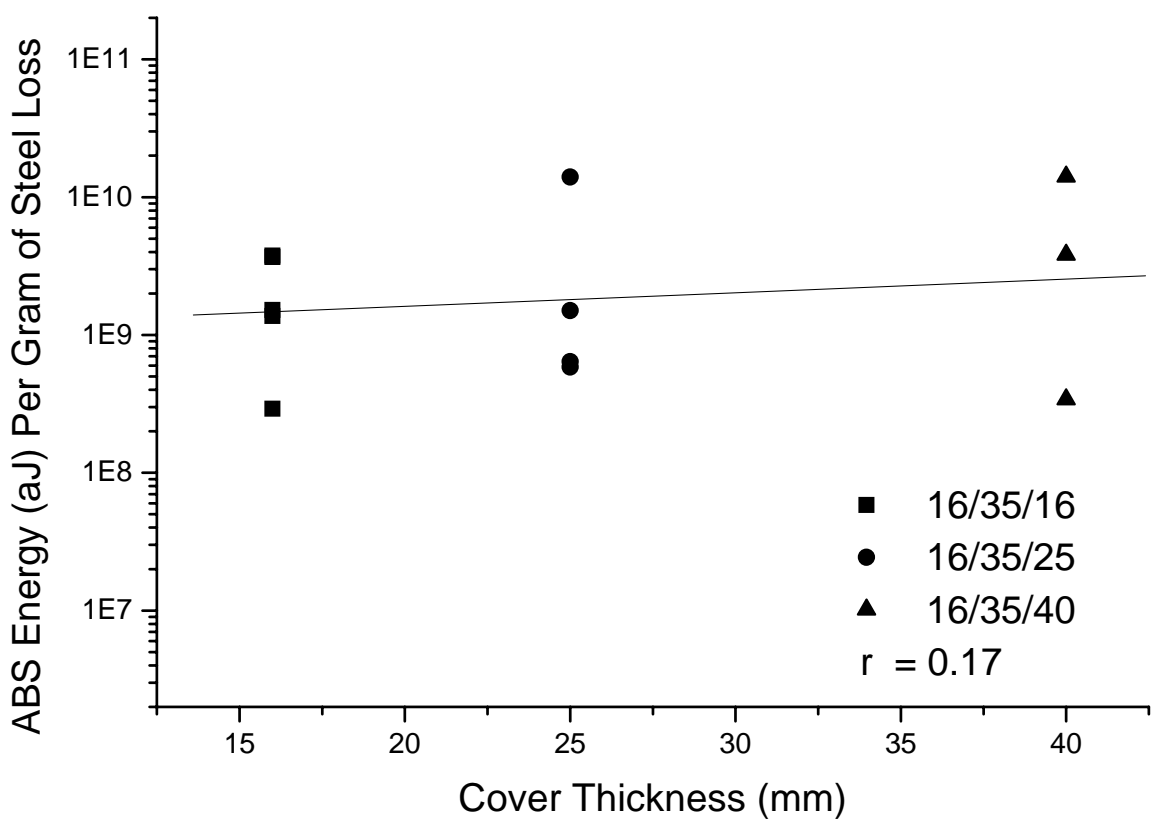

Figure 10 Influence of cover thickness on ABS energy per gram of steel loss 


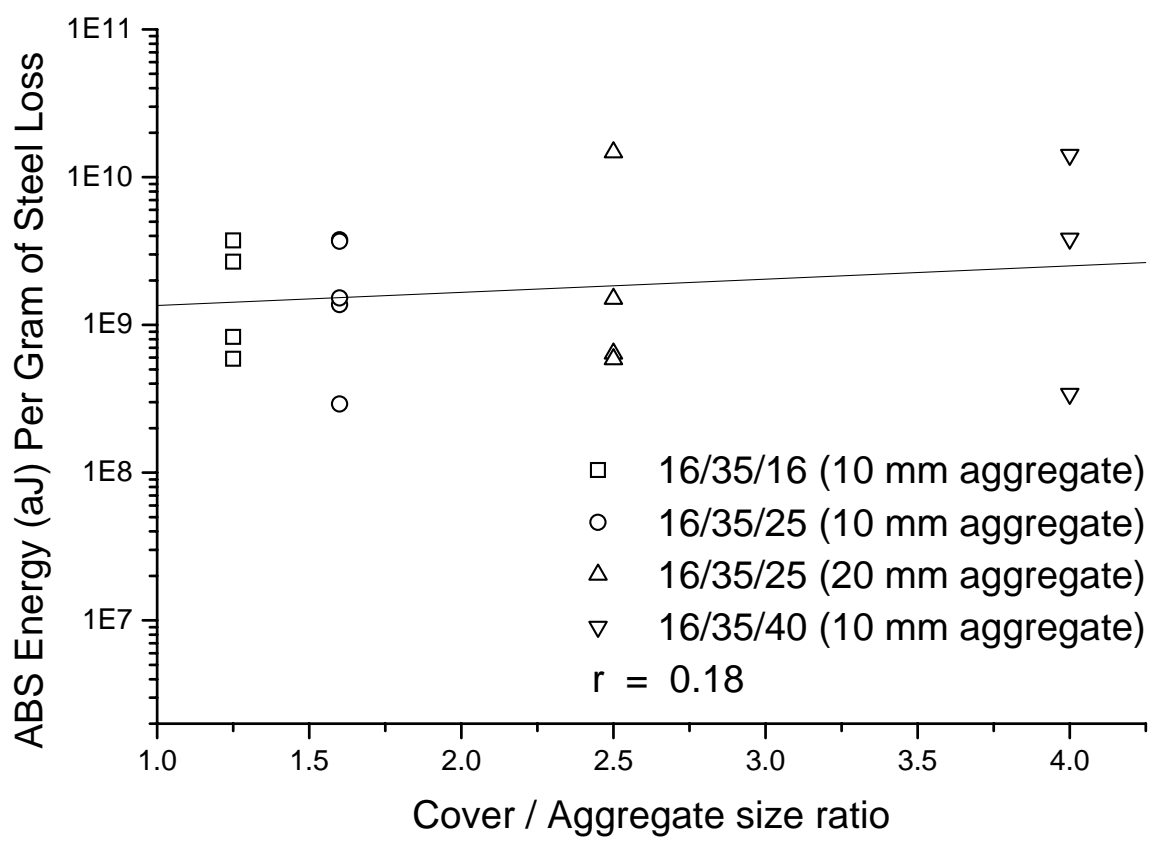

Figure 11 Influence of cover / aggregate ratio 


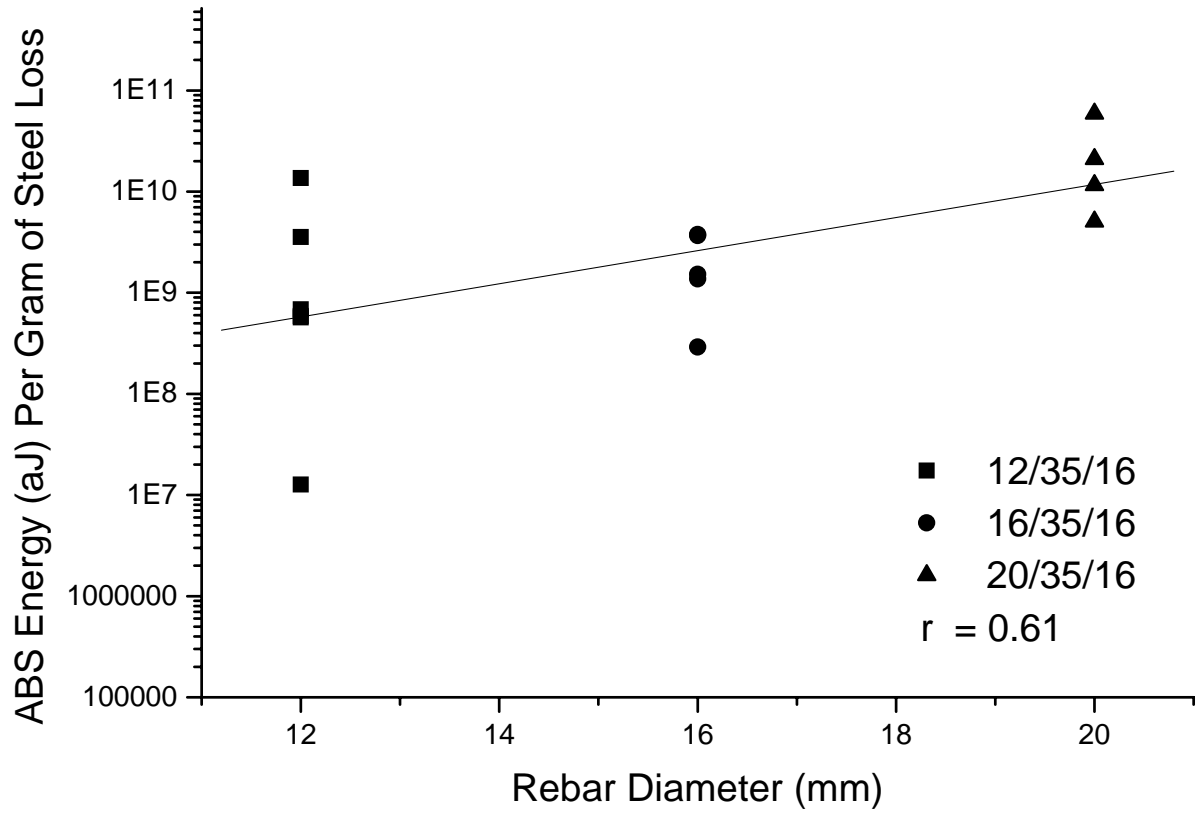

Figure 12 Influence of rebar diameter on ABS energy per gram of steel loss 


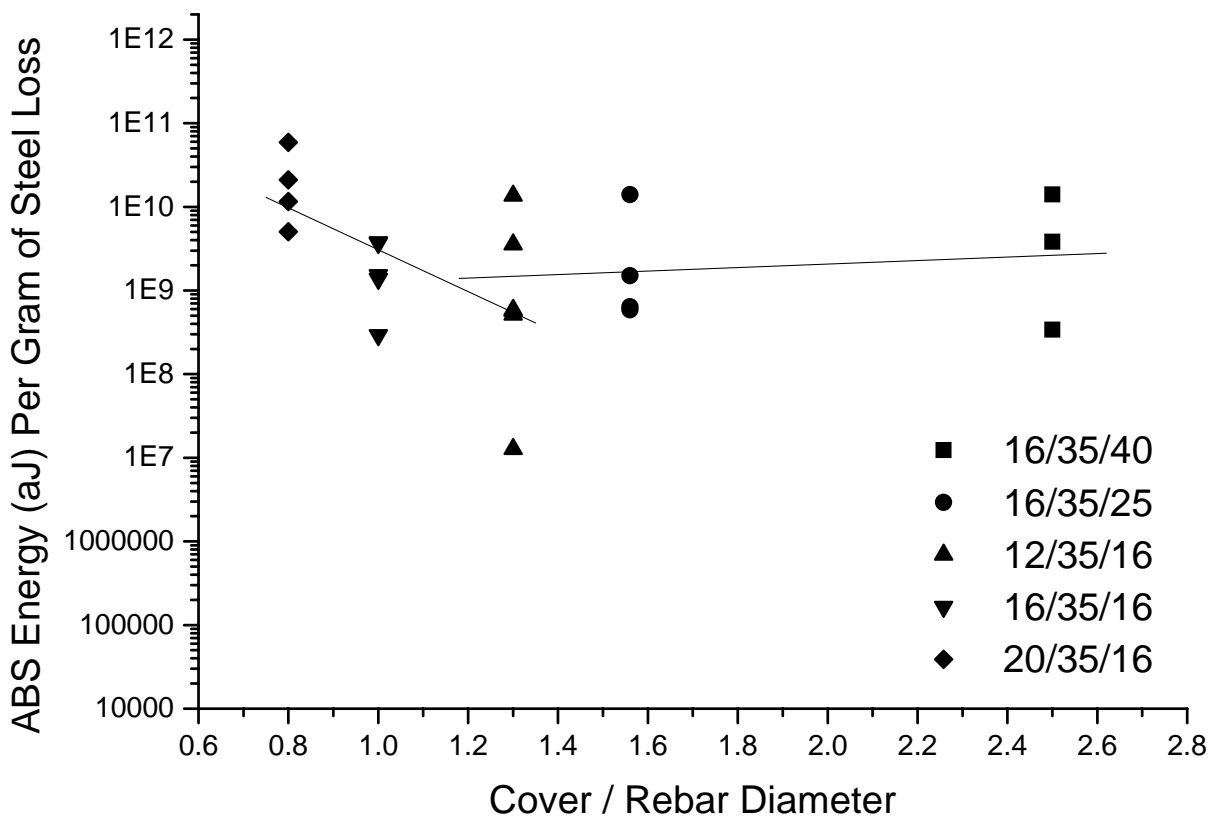

Figure 13 Influence of cover / rebar diameter ratio on ABS Energy per gram of steel loss 


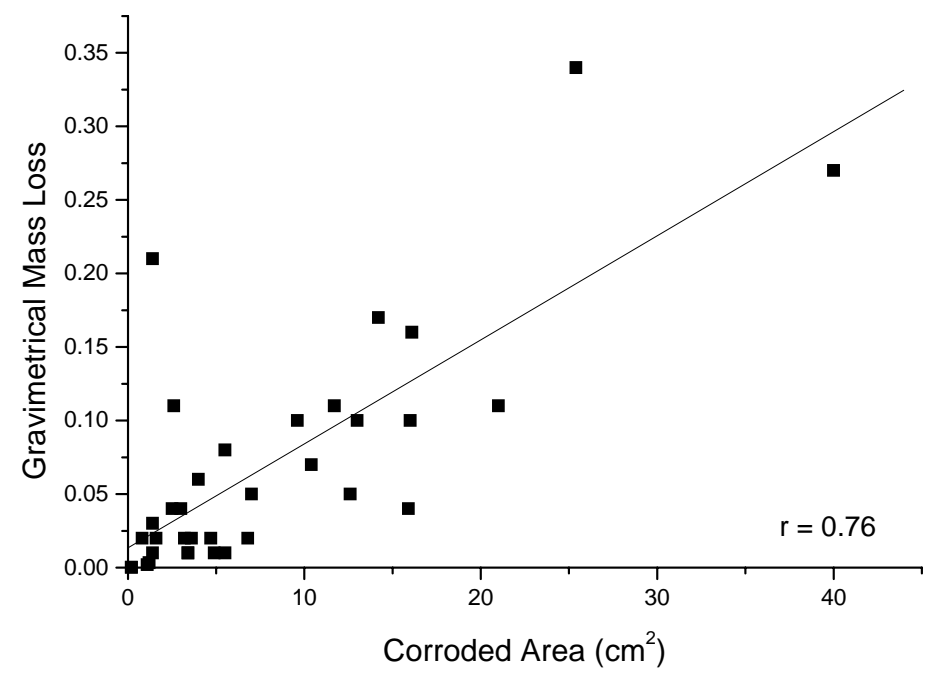

Figure 14 Relationship between corroded area and mass loss 


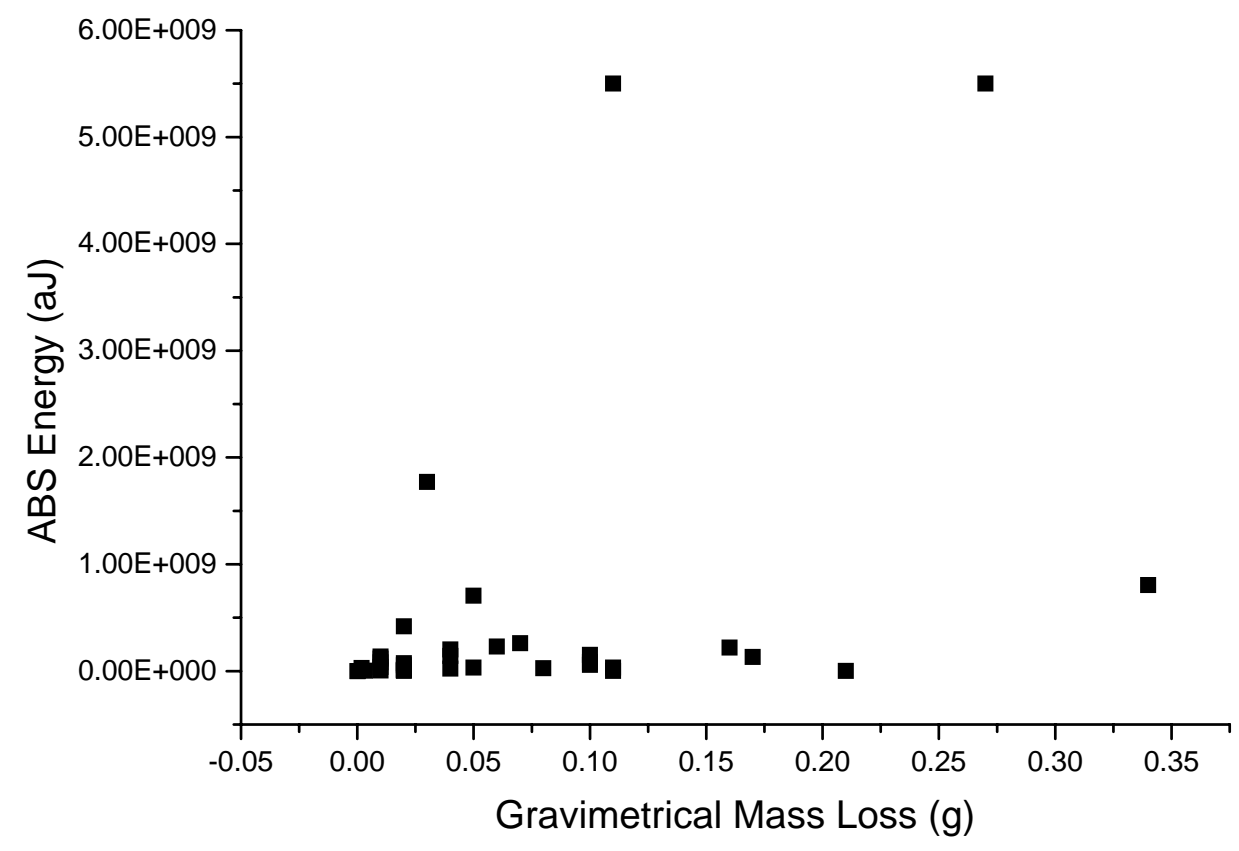

Figure 15 Total ABS Energy vs. Mass Loss 


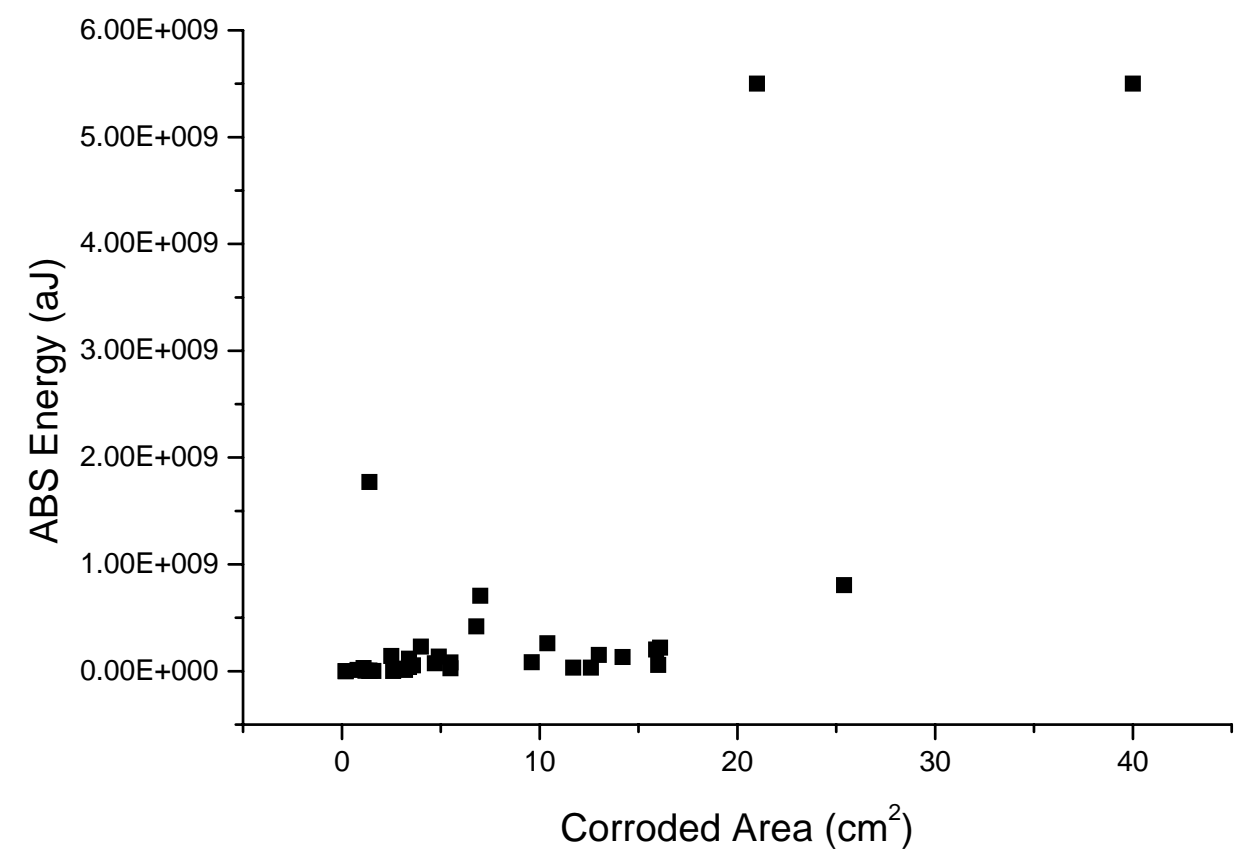

Figure 16 Total ABS Energy vs. Area of Corrosion 